UDC 340.5

LBC 67.08

\title{
THE PROBLEM OF GLOBALIZATION IN LAW: A HISTORIOGRAPHICAL REVIEW
}

\author{
Kseniya V. Shubenkova \\ Volzhsky Branch of Volgograd State University, Volzhsky, Russian Federation
}

\begin{abstract}
Introduction: at the present stage of development, the issues of globalization in law are the most relevant in connection with the actively developing processes of convergence of the legal systems, mutual influence and interpenetration of legal norms of different countries. In this regard, the author aims to study the positive and negative aspects of the process of globalization of law, the existence in these conditions of the national legal system, and its sustainability. The objectives of the study are to determine the essence of the process of globalization, its main characteristics, reflected in the discussions of the Russian scientists. Methods: the methodological framework for this study includes a number of methods of scientific knowledge, among which the main are the methods of systematic analysis and the comparative law method. Results: the author's view grounded in the work is based on the scientific standpoints of the Soviet and modern legal scholars, the main directions of development of the Russian legal system, its features and problems at the present time. The legal analysis of the Russian legislation revealed the dual role of globalization of law. Thus, the analysis of the Russian legal system showed that, on the one hand, there are positive trends in the impact of globalization on Russian law: the Russian statutes include the rules governing the protection of the rights and freedoms of citizens. On the other hand, most authors note that the processes of globalization lead to the destruction of the coherent national legal system, its destabilization, borrowing not only universal norms, but also the norms that have led to negative consequences and worsened the situation of citizens. Conclusions: as a result of the study, the negative consequences of globalization in law, including the Russian one, are revealed when the thoughtless borrowing of international norms and norms of other countries (for example, the reduction of the sphere of sovereignty of a national state, or the adoption of norms without taking into account the national peculiarities) leads to the instability of the entire legal system. The Russian legislation has become intrusive, too detailed and inflexible, and as a result it is impossible to respond to the demands of the society in a timely and effective way. It is established that the domestic legislation is developing in line with the global trends, and the globalization of the legal system is a natural and important process, which must be approached with caution, carefully taking decisions on the introduction of certain rules of other legal systems or the international legislation.
\end{abstract}

Key words: legal globalization, national legal systems, reception, international world statehood.

Citation. Shubenkova K.V. The Problem of Globalization in Law: a Historiographical Review. Legal Concept, 2018, vol. 17, no. 3, pp. 21-27. DOI: https://doi.org/10.15688/lc.jvolsu.2018.3.3

УДК 340.5

ББК 67.08

\section{ПРОБЛЕМА ГЛОБАЛИЗАЦИИ В ПРАВЕ: ИСТОРИОГРАФИЧЕСКИЙ ОБЗОР}

\section{Ксения Владимировна Шубенкова}

Волжский филиал Волгоградского государственного университета, г. Волжский, Российская Федерация

Введение: на современном этапе развития вопросы глобализации в праве являются наиболее актуальными в связи с активно развивающимися процессами сближения правовых систем, взаимовлияния и взаимопроникновения правовых норм разных стран. В связи с этим автором ставится цель исследования положительных и негативных аспектов процесса глобализации права, существования в данных условиях нацио- 
нальной правовой системы, ее устойчивости. Задачами исследования являются определение сущности процесса глобализации, ее основных характеристик, отраженных в дискуссиях российских ученых. Методы: методологическая основа данного исследования включает в себя ряд методов научного познания, среди которых основное место занимают методы системности, анализа и сравнительно-правовой. Результаты: обоснованный в работе авторский взгляд опирается на научные позиции советских и современных ученыхправоведов, основные направления развития российской правовой системы, ее особенности и проблемы в настоящее время. Правовой анализ российского законодательства позволил выявить двоякую роль процесса глобализации права. Так, анализ российской правовой системы показал, что, с одной стороны, налицо положительные тенденции влияния глобализации на российское право: в российские законы включены нормы, регулирующие вопросы защиты прав и свободы граждан. С другой стороны, большинство авторов отмечают, что процессы глобализации ведут к разрушению стройной национальной правовой системы, ее дестабилизации, заимствования не только универсальных норм, но и норм, которые повлекли за собой негативные последствия и ухудшили положение граждан. Выводы: в результате исследования выявлены негативные последствия глобализации в праве, в том числе и в российском, когда бездумное заимствование международных норм и норм других стран (например, сокращение сферы суверенитета национального государства или принятие норм без учета национальных особенностей) приводит к неустойчивости всей правовой системы. Российское законодательство стало носить навязчивый характер, излишне детализировано и негибко, в результате чего невозможно своевременное и эффективное реагирование на требования общества. Установлено, что отечественное законодательство развивается в русле мировых тенденций, и глобализация правовой системы является естественным и важным процессом, к которому необходимо подходить с осторожностью, взвешенно принимая решения по введению определенных норм других правовых систем или международного законодательства.

Ключевые слова: правовая глобализация, национальные правовые системы, рецепция, интернациональная мировая государственность.

Цитирование. Шубенкова К. В. Проблема глобализации в праве: историографический обзор // Legal Concept $=$ Правовая парадигма. -2018 . - Т. 17, № 3. - С. 21-27. - DOI: https://doi.org/10.15688/lc.jvolsu.2018.3.3

\section{Основные подходы к вопросу глобализации в области права}

В настоящее время многие сторонники глобализации отмечают, что данный процесс является объективным [5] и, более того, требующим в результате усложнения социального бытия переосмысления правового регулирования многих общественных отношений [9, c. 252], соответствия национальных правовых систем общепризнанным нормам и принципам международного права.

Обратим в этой связи внимание на работы таких авторов, как А.С. Пиголкин, Б.Н. Топорнин, И.И. Лукашук, О.Э. Лейст, В.С. Нерсесянц и др. В их работах анализировались вопросы влияния глобализационных процессов на государство, развитие российского законодательства, отдельных отраслей российского права, государственно-правовые проблемы включения России в параметры глобального мира.

А.С. Пиголкин полагал, что «автономность не должна противоречить основным глобальным правовым принципам, стандартам, призванным быть общими для каждой национальной юриспруденции. Постепенно уходит в прошлое четкое разделение международного и внутригосударственного права» [1, с. 39].

В.В. Сорокин, полемизируя с А.С. Пиголкиным, утверждает, что международные стандарты в юриспруденции агрессивно навязаны многим странам мира и народам, невзирая на особенности национальных правовых систем, что в итоге, по мнению автора, приводит к кризису самобытных правовых культур [10, с. 397]. Таким образом, в отличие от А.С. Пиголкина, B.В. Сорокин видит в процессах глобализации и проникновения в национальную правовую систему скорее негативное воздействие на право, экспансию западных ценностей.

Поддерживает данную точку зрения и А.А. Данченко, который пишет, что «правочеловеческая догма активно навязана самобытным, самостоятельным и самодостаточным правовым системам. Хотя ценность большинства правозащитных норм и институтов весьма относительная и малопривлекательна для рецепции, инкорпорации в национальное законодательство» [2]. 
Однако в данном случае не учитывается, что полностью самодостаточные правовые системы вряд ли существуют и отдельные процессы глобализации происходят достаточно давно. Они взаимосвязаны и оказывают определенное влияние друг на друга, в том числе и на процессы правотворчества, правоприменения. Нельзя полностью изолировать национальную правовую систему от влияния международных норм. Другой вопрос, что к процессам глобализации надо подходить с учетом национальных особенностей законодательства. Это отмечал Альберт Семенович Пиголкин, говоря о вреде бездумного заимствования и копирования международных норм.

По его мнению, необходимо вести поиск правовых средств, которые позволили бы ограничить негативное влияние глобализации, отрицательных последствий для российской правовой системы [9, с. 253]. Социальные отношения не всегда необходимо подвергать правовой универсализации, унификации и стандартизации. Не может существовать, например, интернациональная мировая государственность, в основе которой лежат единые нормативно-правовые шаблоны, которые уничтожат духовную специфику той или иной нации. А.С. Пиголкин обосновывает: признание однополярной гегемонии в области политического властвования, установления правопорядка уничтожит всякий смысл в существовании понятия государственного суверенитета. Наличие общепризнанных международных норм и принципов не исключает автономность национальных правовых систем. Принудительный импорт нормативно-правовых систем одних стран в другие без должного уважения нормативов последних, без учета их национальной самобытности должен осуждаться правовой мыслью [9, с. 254].

Таким образом, он призывал к весьма осторожному отношению к глобальным процессам и внедрению международных норм в российскую правовую систему, хотя и полагал, что это скорее положительный процесс.

Тем не менее Л.В. Терентьева вполне справедливо полагает, что «дистиллированное», изолированное бытие государства, его правовой системы в международном сообществе в современную эпоху фактически нереализуемо [11, с. 187-200].
Взаимодействие государств на международном уровне, безусловно, в той или иной степени детерминирует внутренний и внешний курс государств, а также вектор развития национального права. Осуществляется поиск компромиссных направлений, корректировки, адаптации своих правовых норм.

\section{О сущности процесса глобализации: плюсы и минусы}

Альберт Семенович определял глобализацию как соединение основных региональных, локальных, национальных проблем в одно целое. По его мнению, процессы глобализации находят свое выражение в «реорганизации и установлении общности политических структур, правовых форм, культурных процессов, науки, сближения национальных традиций, обычаев, менталитета отдельных народов, наций, постепенной унификации всех сторон жизни граждан». Значит, глобализация является средством решения глобальных проблем, сопутствующим современному уровню развития всех общественных процессов, в том числе в области государства и права.

И.И. Лукашук полагает, что глобализацию можно рассматривать в качестве двустороннего процесса. С одной стороны, данный процесс повышает уровень общественного развития, с другой - углубляется социальное неравенство, снижается роль государства и, как следствие, происходит разрушение национальных правовых систем [7, с. 12].

А.С. Пиголкиным был выделен ряд негативных аспектов глобализации: жесткое продавливание транснациональными корпорациями принятия ряда экономических и политических решений в определенных государствах (в том числе и в России - например, вступление в ВТО принесло больше ущерба, нежели экономических выгод); искоренение определенных основ национального права и упразднение отдельных правовых институтов (в настоящее время предлагается упразднение института понятых со ссылкой на то, что во многих странах мира такого института нет); предъявление жестких требований к национальному законодательству (например, приведение национальных норм в соответствие с требованиями международных норм 
без учета национальных особенностей конкретного государства); прохождение массовых протестов и движений антиглобалистов, что является реакцией на то, что, в первую очередь, акцент делается на экономическую сторону и отрицается необходимость и важность социальных аспектов (сейчас мы видим сворачивание многих социальных программ и отказ государства от социальных гарантий) [1, с. 128].

М.А. Лукашев, проанализировав негативные тенденции, считает, что воздействие рассмотренных факторов выражается в эволюционировании предмета правового регулирования во всех его разновидностях и проявлениях [6, с. 34-36].

Изменения норм современного международного права «приводят к интернационализации национального законодательства и к формированию более устойчивой, тесной связи национально-правового и международноправового регулирования» [1, с. 90-91].

По мнению М.Г. Тирских, О.Т. Аббасова, в условиях глобализации процесс сближения правовых систем (который исключает, однако, их полную унификацию) представляется в настоящее время не только неизбежным в контексте общемировой истории, но и единственно возможным, с учетом происходящих правовых преобразований и действия принципа нерушимости суверенитета государств [12, с. 109-110].

Профессор А.О. Иншакова также полагает, что глобализация, детерминантом которой являются экономические процессы, в последующем активно проявляется в праве, где интенсифицируется взаимодействие национальных и международной правовых систем, национальных правовых систем между собой и однопорядковых элементов внутри единой внутригосударственной системы [3, с. 21].

\section{Особенности основных глобальных правовых систем}

B.Е. Чиркин считает, что в связи с процессами глобализации сформировались три основные глобальные правовые системы: мусульманская глобальная правовая система, либерально-полусоциальная правовая система современного капитализма и тоталитарно- социалистическая правовая система. Каждой из них присущи свои особенности. Так, в мусульманской глобальной правовой системе основными источниками права являются Коран, а также Сунна, шариат, главным являются обязанности перед Аллахом, установлено правовое неравенство (в частности женщин, хотя в некоторых странах под влиянием процессов глобализации женщины включаются в состав аш-шуры при монархе - своеобразный совет при правителе) [13, с. 21-24].

В либерально-полусоциальную правовую систему современного капитализма формально включены общечеловеческие ценности, такие как свобода и равенство, справедливость и народный суверенитет, демократия и права человека и др. Главной ценностью данной системы является частная собственность, в праве доминирует принцип формального равенства - равенство возможностей. Воля народа далеко не всегда имеет решающее значение, нет планового руководства производством в масштабах государства, стихия рынка приводит к разрушающим кризисам, нет подлинного социального распределения общественного продукта (прежде всего по труду). В последние десятилетия в конституциях иногда начинает упоминаться также социальная справедливость, социальное партнерство, социальная ответственность, конкуренция не только в экономике, но и на других уровнях, в том числе политическом.

Общими признаками обладает и тоталитарно-социалистическая система: господствующая одна партия - коммунистическая; закрепление в праве неравноправного классового деления общества (рабочий класс - ведущий); отрицание разделения властей и местного самоуправления; права и свободы предоставляются гражданам только в целях строительства социализма; обязательное тотальное государственное планирование и др.

Вместе с тем в социалистической правовой системе, видимо, складывается новая правовая семья. Ее элементы: отказ от концепции диктатуры пролетариата; признание в конституциях необходимости частной собственности и ее важной роли в экономике (что изначально отвергалось в марксизме); положения о регулируемой социалистической ры- 
ночной экономике; тезис о правовом государстве, ранее не признаваемый в марксизмеленинизме, включение в конституции положений о правовом государстве, и др.

Таким образом, идет сближение и некоторых элементов глобальных правовых систем. Так, в странах мусульманского фундаментализма отмечается, что многие институты мусульманского права соотносятся с нормами европейского права. В рамках традиционного капиталистического правового развития стран начинает появляться значительный блок социального законодательства, существенно изменяющий содержание соответствующих норм в правовых системах. В ряде же стран тоталитарного социализма нормами права признаются положения, считавшиеся ранее неприемлемыми в марксизме. Как следствие, подобных процессов конвергенции глобальных правовых систем различных государств, приобретается много принципиально значимого из элементов общеправовой практики и теории.

Тем не менее основополагающие принципы права, характерные для трех глобальных систем, сохраняются, при этом действуют и исконные правовые институты. Данная ситуация связана с тем, что право, обладая определенным консерватизмом, учитывает особенности правовой преемственности и правовой непрерывности.

Полагаем, что в России есть некоторые особенности, которые показывают, что процесс глобализации усугубляет негативные тенденции в развитии национальной правовой системы. Так, А.С. Пиголкин отмечал, что углубление правового регулирования представляет собой один из главных магистральных путей развития современного законодательства. Законодательство стало носить навязчивый характер, является излишне детализированным, и потому негибким [1, с. 20].

Характеризуя проблемы развития российского законодательства, А.С. Пиголкин признавал, что наибольшую степень распространения получает диспозитивная форма, регламентирующая возможность самостоятельного урегулирования сторонами правоотношений основных способов достижения поставленных целей и задач, определения прав и обязанностей посредством договорных процедур (соглашения вместо императива), отсутствие возможности выбора иных вариантов [1, с. 20]. Данное согласительное правовое регулирование конкурирует с законодательным регулированием, что ведет к сокращению сферы суверенитета национального государства. Альберт Семенович подчеркивал приоритет норм права как регулятора общественных отношений. Регулирующая роль правовых норм проявляется в том, что только правовые нормы могут активно преобразовывать и изменять существующие отношения в направлении их более полного соответствия воле и интересам общества [8, с. 39].

Р.А. Каламкарян, соглашаясь с данной точкой зрения, подчеркивает: господство права, представляющее собой способ корреляции основных субъектов в рамках определенной правовой системы, не являющееся абстрактной теоретической конструкцией. Это - действительно востребованный наукой и практикой современной юриспруденции механизм включения субъектов правоотношений в цивилизованный процесс поступательного движения сообщества (будь то государственного или международного) во времени и пространстве [4, с. 75].

Тем не менее, в целом, процесс глобализации А.С. Пиголкин оценивал как позитивный, имеющий в своей основе стремление «способствовать прогрессу и процветанию человечества». Данный процесс призван обеспечить мир и безопасность для всех государств. К сожалению, ученый оказался не совсем прав, и его позиция - это позиция идеалиста.

\section{Выводы}

Активный процесс глобализации ведет в современном мире к разрушению национального самосознания, дестабилизации национальных правовых систем и, тем самым, к снижению роли права в жизни общества. Хотя нельзя не отметить и положительную роль данного процесса: заимствование некоторых универсальных норм и принципов, закрепляющих права и свободы граждан, появление новых отраслей права (например, информационное право), идет сближение и гармонизация правовых систем (хотя есть и некоторые непреодолимые барьеры). 


\section{СПИСОК ЛИТЕРАТУРЫ}

1. Глобализация и развитие законодательства : Очерки / отв. ред. Ю. А. Тихомиров, А. С. Пиголкин. - М. : Городец, 2004. - 464 с.

2. Данченко, А. А. Разрешение коллизий норм европейского и российского права / А. А. Данченко // Российская и европейская правозащитные системы: соотношение и проблемы гармонизации : сборник трудов конференции, Нижний Новгород, 10-13 сент. 2002 г. - Н. Новгород, 2003. - С. 64-68.

3. Иншакова, А. О. Правовая интеграция в сфере корпоративного регулирования: содержание, проблемы, перспективы / А. О. Иншакова // Вестник РУДН. Серия «Юридические науки». - 2011. № 1. - С. 18-41.

4. Каламкарян, Р. А. Россия в универсальном мировом правовом пространстве / Р. А. Каламкарян // Государство и право. - 2013. - № 8. - С. 75-85.

5. Левкина, Т. Глобализация и интеграция: вопросы теории и практики : Доклад на Международной студенческой научной конференции «Глобализация и право: Общепризнанные принципы и нормы национального законодательства» / Т. Левкина // Юридическая Россия : Федеральный правовой портал. - Электронный ресурс. - Режим доступа: http:// law.edu.ru/doc/document.asp?docID=1220803 (дата обращения: 06.03.2018). - Загл. с экрана.

6. Лукашев, М. А. Некоторые аспекты влияния процесса глобализации на предмет правового регулирования / М. А. Лукашев // Теория и практика общественного развития. -2006 . - № 5 . C. 34-36.

7. Лукашук, И. И. Глобализация, государство, право, XXI век / И. И. Лукашук. - М. : Спарк, 2000. $279 \mathrm{c.}$

8. Пиголкин, А. С. Нормы советского права и их толкование / А. С. Пиголкин. - М., 1962.

9. Пиголкин, А. С. Теория государства и права / А. С. Пиголкин. - М. : Городец, 2003. - 253 с.

10. Сорокин, В. В. Юридическая глобалистика / В. В. Сорокин. - М. : Юрлитинформ, 2010. $438 \mathrm{c}$.

11. Терентьева, Л. В. Концепция суверенитета государства в условиях глобализационных и информационно-коммуникационных процессов / Л. В. Терентьева // Право : Журнал Высшей школы экономики. 2017. -№ 1.-С. 187-200.

12. Тирских, М. Г. Аппроксимация права и взаимодействие правовых систем / М. Г. Тирских, О. Т. Аббасов // Сибирский юридический вестник. -2016. - № 4. - С. 109-110.

13. Чиркин, В. Е. Современные глобальные правовые системы: сближение и антагонизм / В. Е. Чиркин // Журнал российского права. - 2015. - № 8. C. 21-24.

\section{REFERENCES}

1. Tikhomirov Yu.A., Pigolkin A.S., eds. Globalizatsiya i razvitie zakonodatelstva: Ocherki [Globalization and the Development of Legislation: Essays]. Moscow, Gorodets Publ., 2004. 464 p.

2. Danchenko A.A. Razreshenie kolliziy norm evropeyskogo i rossiyskogo prava [Resolution of Conflicts of the European and Russian Legal Regulations]. Rossiyskaya $i$ evropeyskaya pravozashchitnye sistemy: sootnoshenie i problemy garmonizatsii: sbornik trudov konferentsii, Nizhniy Novgorod, 10-13 sent. 2002 g. [Russian and European Law-Enforcement Systems: Correlation and the Problems of Harmonization: Conference Proceedings (Nizhniy Novgorod, September 10-13, 2002]. Nizhniy Novgorod, 2003, pp. 64-68.

3. Inshakova A.O. Pravovaya integratsiya v sfere korporativnogo regulirovaniya: soderzhanie, problemy, perspektivy [Legal Integration in the Field of Corporate Regulation: Content, Problems, Prospects]. Vestnik RUDN. Seriya «Yuridicheskie nauki», 2011, no. 1, pp. 18-41.

4. Kalamkaryan R.A. Rossiya v universalnom mirovom pravovom prostranstve [Russia in the Universal Global Legal Space]. Gosudarstvo i pravo, 2013 , no. 8, pp. $75-85$.

5. Levkina T. Globalizatsiya i integratsiya: voprosy teorii i praktiki: Doklad na Mezhdunarodnoy studencheskoy nauchnoy konferentsii «Globalizatsiya $i$ pravo: Obshchepriznannye printsipy $i$ normy natsionalnogo zakonodatelstva» [Globalization and Integration: The Issues of Theory and Practice-Report at the International Student Scientific Conference "Globalization and Law: the Generally Recognized Principles and Norms of National Legislation"]. URL: http://law.edu.ru/doc/document.asp?docID=1220803 (accessed 6 March 2018).

6. Lukashev M.A. Nekotorye aspekty vliyaniya protsessa globalizatsii na predmet pravovogo regulirovaniya [Some Aspects of the Influence of Globalization on the Subject of Legal Regulation]. Teoriya i praktika obshchestvennogo razvitiya, 2006, no. 5, pp. 34-36.

7. Lukashuk I.I. Globalizatsiya, gosudarstvo, pravo, XXI vek [Globalization, State and Law in the $21^{\text {st }}$ Century]. Moscow, Spark Publ., 2000. 279 p.

8. Pigolkin A.S. Normy sovetskogo prava i ikh tolkovanie [The Rules of Soviet Law and Their Interpretation]. Moscow, 1962.

9. Pigolkin A.S. Teoriya gosudarstva i prava [Theory of State and Law]. Moscow, Gorodets Publ., 2003. 253 p.

10. Sorokin V.V. Yuridicheskaya globalistika [The Legal Globalistics]. Moscow, Yurlitinform Publ., 2010. 438 p.

11. Terentyeva L.V. Kontseptsiya suvereniteta gosudarstva $\mathrm{v}$ usloviyakh globalizatsionnykh i 
informatsionno-kommunikatsionnykh protsessov [The Conception of State Sovereignty under Conditions of Globalization and Infor-Communication Processes]. Pravo: Zhurnal Vysshey shkoly ekonomiki, 2017, no. 1, pp. 187-200.

12. Tirskih M.G., Abbasov O.T. Approksimatsiya prava i vzaimodeystvie pravovykh sistem
[Approximation of Law and the Interaction of Legal Systems]. Sibirskiy yuridicheskiy vestnik, 2016, no. 4, pp. 109-110.

13. Chirkin V.E. Sovremennye globalnye pravovye sistemy: sblizhenie i antagonizm [The Contemporary Global Legal Systems: Convergence and Antagonism]. Zhurnal rossiyskogo prava, 2015, no. 8, pp. 21-24.

\section{Information about the Author}

Kseniya V. Shubenkova, Candidate of Sciences (Jurisprudence), Associate Professor, Department of Theory and History of Law and State, Volzhsky Branch of Volgograd State University, 40 let Pobedy St., 11, 404133 Volzhsky, Russian Federation, shubenkova34@yandex.ru.

\section{Информация об авторе}

Ксения Владимировна Шубенкова, кандидат юридических наук, доцент кафедры теории и истории права и государства, Волжский филиал Волгоградского государственного университета, ул. 40 лет Победы, 11, 404133 г. Волжский, Российская Федерация, shubenkova34@yandex.ru. 